\title{
Formação de recursos humanos e produção científica em Educação em Ciências
}

Formation of human resources and scientific production in Science Education

\author{
Ediane Maria Gheno' \\ Scheila Raquel Rempel ${ }^{2}$ \\ Luiz Felipe Sfoggia da Mata ${ }^{3}$ \\ Jessié Martins Gutierres ${ }^{4}$ \\ Regina Maria Guaragna ${ }^{5}$ \\ Rochele Loguercio ${ }^{6}$ \\ Luciana Calabró ${ }^{7}$ \\ Diogo Onofre Souza ${ }^{8}$
}

\section{Resumo}

Este artigo investigou se o número de orientados (mestres e doutores) por docente impacta na média de documentos em periódicos por orientado e avaliou quais as contribuições para a produção de conhecimento científico para área de Educação em Ciências no contexto do Programa de Pós-Graduação em Educação em Ciências: Química da Vida e Saúde-PPGQVS (Universidade Federal do Rio Grande do Sul, Universidade Federal de Santa Maria, Universidade Federal do Rio Grande e Universidade Federal do Pampa), de 2013 a 2019. O referencial teórico discute o Sistema de Avaliação da Coordenação de Aperfeiçoamento de Pessoal de Nível Superior (CAPES), área de Ensino, e a Educação em Ciências no Brasil. É uma pesquisa descritiva, com abordagem qualitativa e quantitativa, de natureza aplicada, que utiliza indicadores bibliométricos e cientométricos e Análise de Conteúdo (Bardin). Os dados foram coletados na Plataforma Sucupira e no site dos periódicos. Os resultados evidenciaram que o número de orientados por docente não impacta na média de documentos por orientado. As temáticas mais pesquisadas foram "Ensino de Ciências" (26,0\%), "Formação de Professores" (24,3\%) e "Políticas Educacionais" (15,7\%). A partir da formação de mestres e doutores, aliada à produção de conhecimento científico, se pode constatar a contribuição do PPGQVS para a área de Educação em Ciência no país.

Palavras chave: Genealogia acadêmica; Perfil de docentes; Temas prioritários em Educação em Ciências.

\footnotetext{
${ }^{1}$ Universidade Federal do Rio Grande do Sul | ghenoediane@gmail.com.

${ }^{2}$ Universidade Federal do Rio Grande do Sul | rempelscheila@gmail.com

${ }^{3}$ Universidade Federal do Rio Grande do Sul | luiz.sfoggia@ufrgs.br.

${ }^{4}$ Universidade Federal de Ciências da Saúde de Porto Alegre | jessiegutierres@hotmail.com.

${ }^{5}$ Universidade Federal do Rio Grande do Sul | rguaragna@terra.com.br

${ }^{6}$ Universidade Federal do Rio Grande do Sul | rochelel@gmail.com.

${ }^{7}$ Universidade Federal do Rio Grande do Sul | luciana.calabro.berti@gmail.com.

${ }^{8}$ Universidade Federal do Rio Grande do Sul | diogo.bioq@gmail.com.
} 


\section{Abstract}

This article investigated whether the number of supervised students (masters and doctors/PhD) per professor impacts in the average number of periodic documents per student, and it evaluated the contributions to the production of scientific knowledge for the area of Science Education in the context of the Programa de Pós-Graduação em Educação em Ciências: Química da Vida e Saúde-PPGQVS (Universidade Federal do Rio Grande do Sul, Universidade Federal de Santa Maria, Universidade Federal do Rio Grande, and Universidade Federal do Pampa), from 2013 to 2019. The theoretical framework discusses the Coordenação de Aperfeiçoamento de Pessoal de Nível Superior (CAPES) Evaluation System in the area of Teaching and Education in Science in Brazil. It is a descriptive study, with a qualitative and quantitative approach, which uses mixed analysis techniques: bibliometrics and scientometrics indicators and Content Analysis (Bardin). Data collection took place on the Sucupira Platform and on the periodical's website. As a results, it was identified that the average number of documents per student is not affected by the number of students who have their professor. The most researched topics were "Science Teaching" (26.0\%), "Teacher Training" (24.3\%) and "Educational Policies" (15.7\%). Based on the training of masters and doctors along with the production and dissemination of scientific knowledge, the contribution of the PPGQVS to the area of Science Education in the country becomes evident.

Keywords: Academic genealogy; Professor profile; Priority research in Science Education.

\section{Introdução}

O desempenho dos Programas de Pós-Graduação (PPGs) no Brasil é periodicamente monitorado e avaliado pela Coordenação de Aperfeiçoamento de Pessoal de Nível Superior (CAPES) por meio de seu Sistema de Avaliação. Os Comitês de cada área avaliada (49 áreas) emitem, ao final dos processos avaliativos, Relatórios de Avaliação e Fichas de Avaliação com os pareceres em relação à proposta do programa, à produção intelectual, ao corpo docente, ao corpo discente, à inserção social e à internacionalização de cada PPG.

Apesar das informações relevantes descritas nestes documentos emitidos pelas CAPES na área de Ensino (CAPES, 2017; 2017a), a cultura da avaliação pelos próprios PPGs é de suma relevância para que outros modos de leitura dos dados possam ser analisados e avaliados. Por isso, a presente pesquisa investiga duas questões que podem ser complementares à avaliação da CAPES da área de Ensino: i) O número de orientados (mestres e doutores) por docente impacta na média de documentos por orientado? ii) No que se refere às temáticas pesquisadas, quais são as contribuições para a produção de conhecimento científico para área de Educação em Ciências? Esta pesquisa é aplicada no Programa de Pós-Graduação em Educação em Ciências: Química da Vida (PPGQVS) no período de 2013 a 2019, investindo em três objetivos analíticos: i) analisar a colaboração científica resultante da relação Docente-Orientado nos documentos publicados em periódicos com Qualis; ii) analisar a distribuição de mestres e doutores titulados por docente; iii) identificar o número de documentos por docente com seus orientados e iv) analisar os temas priorizados nas pesquisas.

O PPGQVS iniciou suas atividades em 2008, atuando em caráter de Forma Associativa entre: Universidade Federal do Rio Grande do Sul (UFRGS), Universidade Federal de Santa 
Maria (UFSM), Universidade Federal do Rio Grande (FURG) e Universidade Federal do Pampa (UNIPAMPA). Com curso de mestrado e de doutorado acadêmicos reconhecidos com nota 4 pela CAPES (CAPES, 2020), o PPGQVS concentra linhas de pesquisa nas áreas de ensino, de educação e de avaliação em ciências.

Nos processos formais de comunicação científica, uma das formas de mensurar a colaboração é por meio da coautoria nos documentos (KATZ; MARTIN, 1997). Em relação à genealogia acadêmica, a colaboração ocorre entre orientador-orientando. Essa relação sempre manteve um papel de destaque, principalmente no Brasil, onde a maior parte da produção científica é realizada pelos PPGs (HILÁRIO; GUTIERRES; CABRINI, 2017). Por isso, no presente artigo, aplicaram-se indicadores bibliométricos e cientométricos (PRICE, 1986; GLÄNZEL, 2003) de produção científica (número de documentos) e de coautoria (colaboração entre Docente-Orientado). E, para analisar os temas priorizados nas pesquisas, aplicou-se Análise de Conteúdo (BARDIN, 2009). Para Ferreira e Loguercio (2014), esta técnica é de vasta aplicabilidade em pesquisas qualitativas em Educação em Ciências principalmente quando há a demanda de sistematização de conteúdo para interpretar e inferir significado.

Importante destacar dois estudos que avaliaram o PPGQVS. O primeiro estudo, de Pereira et al. (2014), aplicou a Análise de Redes Sociais-ARS para verificar as tendências em publicações em coautoria pelos docentes do PPGQVS da UFRGS de 2005-2013. Os resultados apontam crescimento da produção científica em coautoria, mostrando também elementos de conexão entre os docentes e seus discentes. O segundo estudo, de Viggiani, Calabró e Souza (2017), analisou o corpo docente sob a perspectiva de sua produção intelectual e da participação, ou não, como orientadores em outros PPGs, 2010-2014. Os autores constataram algumas diferenças entre os docentes com dedicação exclusiva e os que atuaram como orientadores em outros programas.

Portanto, as abordagens aplicadas nesta investigação mostram-se relevantes para a obtenção de informações adicionais ao Sistema de Avaliação e às pesquisas realizadas anteriormente, resultando em um amplo Monitoramento e Avaliação (M\&A) de desempenho institucional que permite avaliar o impacto do PPG na formação de recursos humanos e na produção de conhecimento para a área de Educação em Ciências. A seguir, fez-se uma intersecção com o Sistema de Avaliação da CAPES (área de Ensino), mostrando a aplicabilidade desta pesquisa e discutiu-se brevemente a Educação em Ciências no Brasil.

\section{Sistema de avaliação da CAPES: Área de Ensino}

A área de Ensino conta com 181 PPGs, sendo 64 na região Sudeste, 45 no Sul, 32 no Nordeste, 21 no Centro-Oeste e 19 no Norte (CAPES, 2019a). Trata-se de uma área de pesquisa translacional que transita entre a ciência básica e a ciência aplicada. Para esta área, os conhecimentos gerados (pesquisa, ensino e extensão) são estratégicos para as mudanças educacionais, pois buscam contribuir para o desenvolvimento tecnológico do país, para os processos de formação e para a melhoria das condições de vida da população (CAPES, 2019a).

A nova Ficha de Avaliação (CAPES, 2019) prevê o M\&A dos PPGs a partir de três quesitos: 1) Proposta do Programa; 2) Formação e 3) Impacto na Sociedade. Esta nova estratégia se caracteriza por ser multidimensional ao permitir acomodar a diversidade de vocações e os objetivos dos PPGs (BARATA, 2019) por meio de abordagens 
quanti/qualitativas. Para Barata (2019), mesmo que o tamanho do Sistema Nacional de PósGraduação force o uso de indicadores quantitativos, é necessário que haja um equilíbrio de abordagens para alcançar significados distintos do trabalho exercido pelos PPGS na sociedade. Neste contexto, o presente artigo faz uma intersecção com alguns dos itens da Ficha de Avaliação (CAPES, 2019), conforme Figura 1.

Em relação ao Quesito 1, item 1. 2, identificou-se o perfil dos docentes, pois a área de Ensino tem valorizado nos PPGs a composição do corpo docente com formação em diferentes áreas de conhecimento: "[...] a interdisciplinaridade tem papel estratégico no sentido de estabelecer a relação entre saberes, [...], apresentando-se como um conhecimento que responde aos desafios do saber complexo". (CAPES, 2019a, p. 8).

No item 1.4, que trata da autoavaliação, aplicou-se um método que permitiu realizar um M\&A complementar ao Sistema de Avaliação da CAPES. Tal proposta vai ao encontro das diretrizes da área de Ensino, visto que a Avaliação Institucional pode contribuir de modo substancial no planejamento estratégico do programa, prevendo ações de mudanças estruturais para as próximas avaliações.

No Quesito 2, item 2.1, que trata da qualidade e adequação das teses, dissertações em relação às áreas de concentração e linhas de pesquisa do PPG, analisaram-se os temas priorizados dos documentos em periódicos com Qualis. Este item se interliga com os itens descritos a seguir.

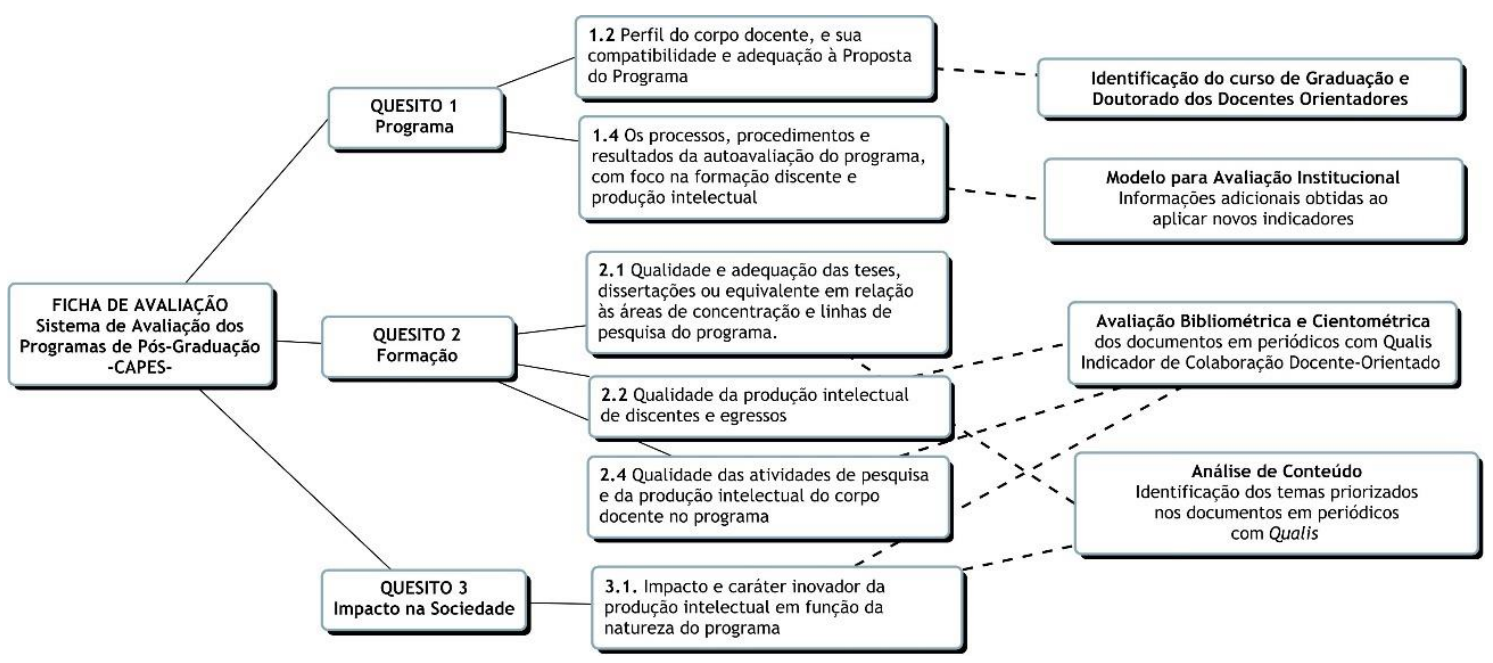

Figura 1. Quesitos da Ficha de Avaliação da CAPES e dimensões abordadas nesta pesquisa.

Fonte: Adaptado de CAPES (2019)

Para atender aos itens 2.2 e 2.4, aplicaram-se indicadores bibliométricos e cientométricos (produção e coautoria) a fim de identificar o número de documentos por estratos Qualis e a coautoria entre Docente-Orientado. A bibliometria e a cientometria, como técnicas de análises quantitativas, possibilitam avaliar o crescimento e o desenvolvimento da C\&T. Essas métricas vêm sendo amplamente utilizadas para definição de políticas públicas pelos órgãos governamentais e pelas agências de fomento e de financiamento (PRICE, 1986; GLÄNZEL, 2003).

No Quesito 3, item 3.1, a área de Ensino considera inovação os conhecimentos produzidos que atendam às demandas sociais e que possam contribuir para a produção de serviços à comunidade e para a proposição de políticas públicas. A área reconhece processos inovadores àqueles que visam a redução das defasagens existentes entre a 
pesquisa científica e o ensino. Portanto, "[...] é esperado que ações e projetos desenvolvidos nos PPGs da área visem à transformação da prática dos professores, contando, para isso, com a constituição do professor como pesquisador, inclusive de sua própria prática". (CAPES, 2019a, p. 9). Para mensurar o impacto dos PPGs na sociedade, a área de Ensino avaliará a qualidade da produção intelectual pelo Qualis dos periódicos. Levando em conta essa perspectiva de avaliação, é importante, além de identificar o número de documentos por Qualis, sinalizar os temas priorizados nas pesquisas a fim de identificar as contribuições para a produção de conhecimento científico na área.

\section{Educação em Ciências no Brasil}

A educação em ciências no Brasil não é recente. No século XIX, a corrente positivista das ciências foi suficiente para influenciar os cientistas e intelectuais brasileiros, valorizando uma ciência dogmática, determinada na época como um conjunto de conhecimentos que deveria ser aprendido e aplicado para a população (PAIM, 1980; SCHWARTZMAN, 1991). Em 1932, o "Manifesto dos Pioneiros da Educação Nova" indicava que a educação em ciências seria desenvolvida a partir do ensino médio e superior. Entretanto, nessa época, a única maneira de se formar em ciências era por meio do trabalho direto como discípulo de um pesquisador já estabelecido. Para Vaccarezza (1999), até o final da década de 70, o pensamento a respeito da produção científica e tecnológica brasileira foi se constituindo como um discurso teórico-ideológico, originado na práxis científica e política de seus idealizadores. Esse pensamento apresentava pouca reflexão teórica e conceitos mais próximos às suas experiências imediatas e pessoais (VACCAREZZA, 1999). Já a partir dos anos 1980, vários estudos começaram a valorizar a Educação em Ciências, devido às suas contribuições na construção de uma sociedade democrática e integradora e que talvez pudesse superar as novas expressões do elitismo e da fragmentação social. Em razão da crítica sobre a dependência cultural do Brasil por nações estrangeiras, pretendeu-se transformar a produção científica e tecnológica e a percepção de suas relações com a sociedade, contrariamente aos movimentos intelectuais dos anos 1960 e 1970, desenvolvendo a ideia de um papel social dessas atividades.

A formação científica e tecnológica no Brasil está expressa nos "Parâmetros Curriculares Nacionais" (BRASIL, 1997). Segundo Schwartzman e Christophe (2009), o objetivo principal da Educação em Ciências nas escolas não é a formação de cientistas e pesquisadores, mas a difusão das atitudes e dos valores associada à postura indagativa e crítica, própria das disciplinas relacionadas com a ciência. Em termos conceituais, "[....] educação em ciências" pode significar muitas coisas, desde a difusão de conhecimentos gerais sobre a ciência e a tecnologia como fenômenos sociais e econômicos, até a formação nos conteúdos específicos de determinadas disciplinas [...]" (SCHWARTZMAN; CHRISTOPHE, 2009, p. 9).

O oferecimento de uma sólida formação científica e pedagógica aos professores sempre foi considerada uma condição essencial para a melhoria do ensino de ciências no Brasil. No entanto, nas décadas de 1980 e 1990, parte significativa das propostas de melhoria do ensino de ciências trazia graves problemas epistemológicos e didáticos, dificultando a formação do sujeito crítico, consciente e participativo. A formação desses profissionais acompanhou as diretrizes educativas estrangeiras, concretizou as singularidades políticoeconômicas da época e reproduziu, em muitos casos, os interesses da classe dominante (NASCIMENTO; FERNANDES; MENDONÇA, 2010). 
As discussões sobre o desenvolvimento da Educação em Ciências no Brasil devem ter como premissa a construção de um ensino de ciências de qualidade e que às possibilidades didáticas para o ensino de ciências na escola sejam oferecidas aos sujeitos. No Ensino Superior e na PG, o ensino pode assumir uma formação reflexiva e consciente do seu papel enquanto formação científica de professores, uma vez que a construção de uma sociedade democrática, justa e equitativa pressupõe, também, uma formação científica que permita ao cidadão perceber e agir no mundo que por si é científico-tecnológico. Isso requer esforço não apenas dos professores da escola, mas também das instituições de ensino superior e de outros espaços formativos, pois o estudante deve experimentar uma vivência científica capaz de refletir na construção de conhecimentos numa perspectiva emancipatória (MENEZES, 1987).

\section{Materiais e métodos}

É uma pesquisa descritiva, com abordagem quanti/qualitativa, de natureza aplicada, que aplica técnicas mistas de análise da produção científica e de formação de recursos humanos do PPGQVS: i) Bibliometria e cientometria, nível de agregação micro (GLÄNZEL, 2003), com base nos indicadores: número de documentos em periódicos, Qualis, coautoria, número de docentes e número de mestres e doutores titulados) e ii) Análise de Conteúdo (BARDIN, 2009), ferramenta de pesquisa para a exploração interpretativa de documentos a fim de analisar os temas priorizados nas pesquisas.

Conforme Figura 2, todos os dados do PPGQVS de 2013-2016 (Quadrienal 2017) foram extraídos na Plataforma Sucupira via CAPES, selecionando-se o ícone da área Ensino (46. Ensino), conforme CAPES (2017). Nesta planilha, foi possível identificar: código do PPGQVS, título do documento (artigos, artigos de revisão), ano de publicação, título do periódico/ISSN, Qualis (Quadrienal 2017), docentes permanentes e colaboradores com orientações concluídas e lista de mestres e de doutores titulados. Os dados de 2017-2019 (Quadrienal 2021, incompleta) que ainda não estão disponíveis na Plataforma Sucupira via CAPES, foram coletados na Plataforma Sucupira via Secretaria do PPGQVS e disponibilizados aos autores para esta pesquisa, antes do processo de Recoleta da CAPES. Para ambas as planilhas, foi necessário coletar informações adicionais dos documentos (entendido aqui como produção científica ou produção intelectual) no site de cada periódico. A Plataforma Sucupira é uma importante ferramenta de gestão da informação da Pós-Graduação. Contudo, não há informações completas da produção intelectual como: lista completa dos autores, resumo, palavras-chave, dentre outras informações pertinentes para um M\&A de desempenho mais aprofundado. Estas lacunas na Plataforma Sucupira já foram relatadas por Gheno (2019).

Considerou-se produção científica por orientado, os documentos em periódicos com Qualis que apresentaram genealogia acadêmica, ou seja, com colaboração DocenteOrientado. Para isso, consideraram-se somente os documentos cuja primeira autoria é o orientado, enquanto o docente se encontra como coautor, por último ou no meio (Figura 2), método adaptado de Gheno et al. (2019a). O tempo de titulação dos mestres e dos doutores foi levado em conta na distribuição do número documentos por orientado, que foi de 2013-2019. A aplicação deste método se justifica pelo fato de o PPGQVS exigir que os resultados de pesquisa sejam publicados (em coautoria com seus orientadores) em 
periódicos com Qualis na área de Ensino, conforme os Regimentos de cada sede do PPGQVS:

- $\quad$ UFRGS: Mestrado: 1 artigo publicado ou aceito, preferencialmente com Qualis de A-B2; Doutorado: 1 artigo publicado ou aceito e 1 submetido, com Qualis de A-B2 (UFRGS, 2017);

- $\quad$ UFSM: Mestrado: sem pré-requisito de publicação; Doutorado: 1 artigo publicado ou aceito e 1 submetido, Qualis superior a B2 (UFSM, 2014);

- $\quad$ FURG: Mestrado: sem pré-requisito de publicação; Doutorado: 1 artigo publicado ou aceito, Qualis mínimo B (FURG, 2017);

- UNIPAMPA: Mestrado: 1 artigo submetido após a defesa, Qualis superior a B1; Doutorado: 1 artigo publicado ou aceito e 1 submetido após a defesa, Qualis superior a B1 (UNIPAMPA, 2017).

Para analisar se o número de orientados (mestres e doutores titulados no período de 2013-2019) por docente impacta na média de documentos por orientado (documentos/orientado), foi realizado tratamento estatístico por meio do teste ANOVA de uma via, utilizando o Software GraphPad Prism, versão 7.0 (San Diego, CA, USA).

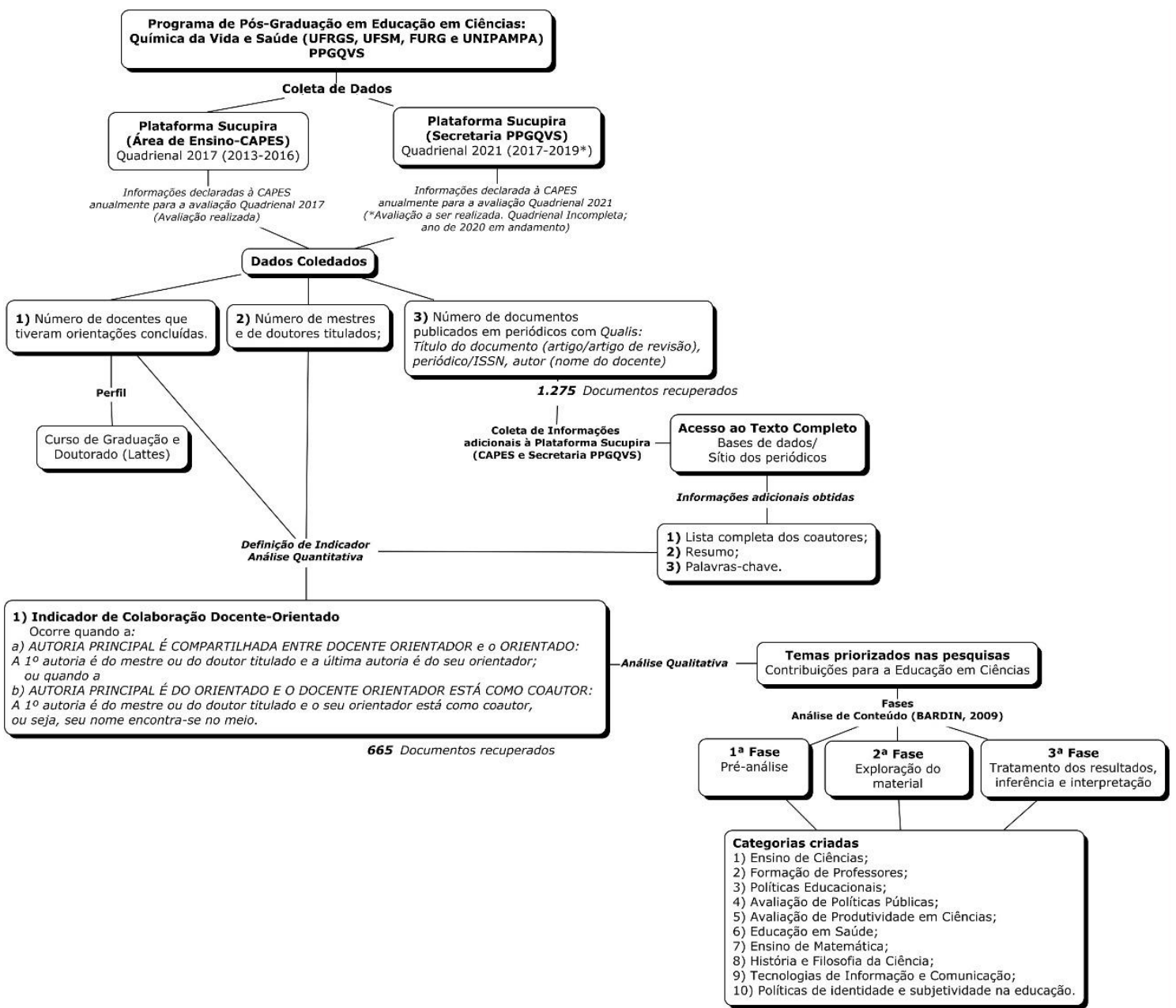

Figura 2. Esquema metodológico. Fonte: Elaborado pelos autores, com base em dados da pesquisa.

O perfil dos docentes foi analisado pelo curso de graduação e pela Pós-Graduação (Doutorado), classificado pelas oito grandes áreas do conhecimento. A coleta se deu por meio do Currículo Lattes, utilizando a ferramenta Scriptlattes (MENA-CHALCO; CESAR 
JUNIOR, 2009). Os temas priorizados nas pesquisas foram analisados a partir de técnicas de exploração do significado dos conteúdos dos resumos e das palavras-chave dos documentos, utilizando a Análise de Conteúdo (BARDIN, 2009). A leitura foi feita pelos autores da pesquisa, seguindo as fases propostas por Bardin (2009). O critério de análise foi por categorização através do nível semântico. Para este tópico, a análise foi restrita aos documentos em periódicos com Qualis A1 e A2, resultando em 10 categorias (Figura 2).

\section{Resultados e discussão}

Em relação ao perfil dos 112 docentes credenciados de 2013-2019, os resultados apontam que o PPGQVS segue as diretrizes da área de Ensino ao apresentar um corpo docente multidisciplinar, oriundo de diversas áreas do conhecimento tanto na graduação como também no doutorado, Figura 3 (A, B). A maioria dos docentes (47) se graduaram em cursos da grande área Ciências Exatas e da Terra (por exemplo, Física, Química, Matemática). No doutoramento, observou-se uma mudança, pois a área Ciências Humanas foi predominante, com 53 docentes. Essa mudança se justifica pelo fato de que 26 docentes oriundos das Ciências Exatas e da Terra migraram para a grande área Ciências Humanas no doutorado, em cursos como: Educação em Ciências, Ensino de Ciências e Ensino de Física, demonstrando a consolidação da área de Ensino nos processos formativos na PG.

A

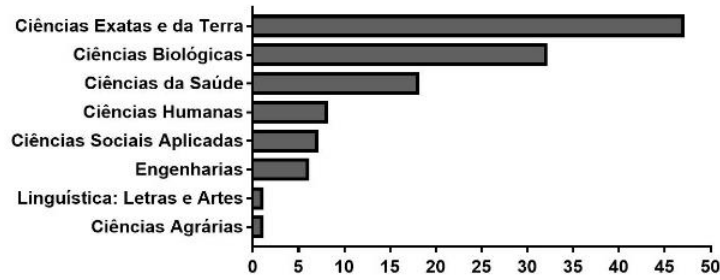

B Grande Área - Doutorado

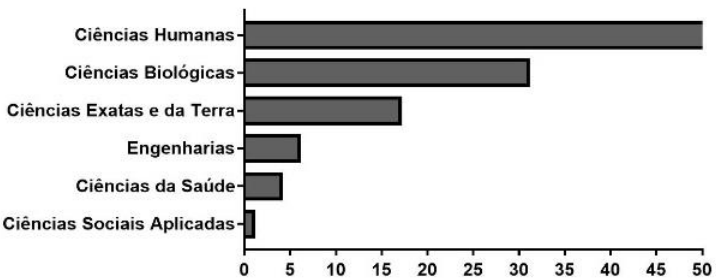

Figura 3. Perfil dos docentes do PPGQVS (2013-2019) por grande área: (A) graduação e (B) doutorado. Legenda: (3A) Oito docentes são graduados em mais de um curso. Fonte: Elaborado pelos autores, com base em dados da pesquisa.

Estes docentes foram responsáveis pela titulação de 365 mestres e 302 doutores (totalizando 667), sendo 47,4\% deles no período de 2013-2016 e 52,3\%, no período de 2017-2019 (Figura 4). O crescimento de mestres e de doutores titulados foi linear.

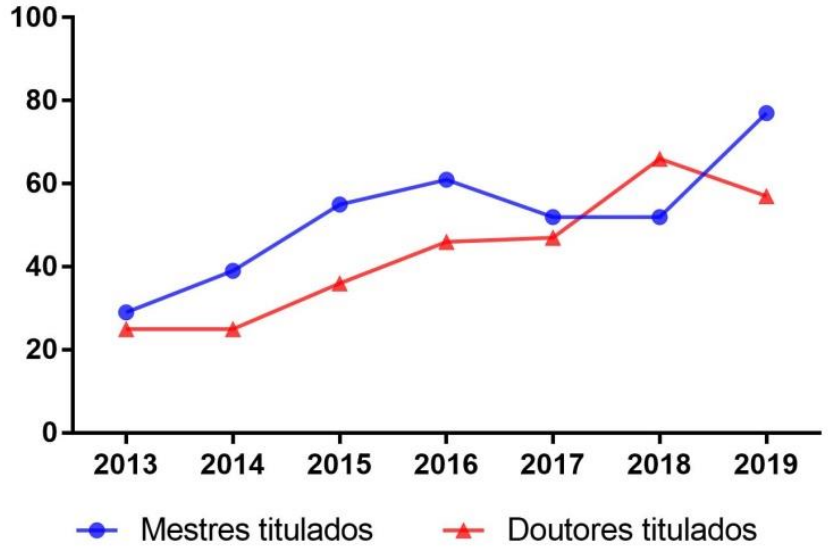

Figura 4. Número de mestres e de doutores titulados pelo PPGQVS de 2013-2019. Fonte: Elaborado pelos autores, com base em dados da pesquisa. 
Ao analisar a produção científica, de 2013 a 2016, identificou-se que o PPGQVS declarou à CAPES 474 documentos em periódicos com Qualis e, no período de 2017-2019, foram 801, totalizando 1.275 documentos. Em relação aos estratos Qualis desses documentos, constatou-se que no período de 2013-2017 predominou documentos publicados em periódicos no estrato B1 (119 documentos; representando 25,1\% do total), com deslocamento para A2 (101; 21,3\%), Figura 5A. No período de 2017-2019, continua predominando documentos em periódicos no estrato B1 (221 documentos; 27,6\%), com deslocamento para B2 (211; 26,3\%), Figura 5B.

A

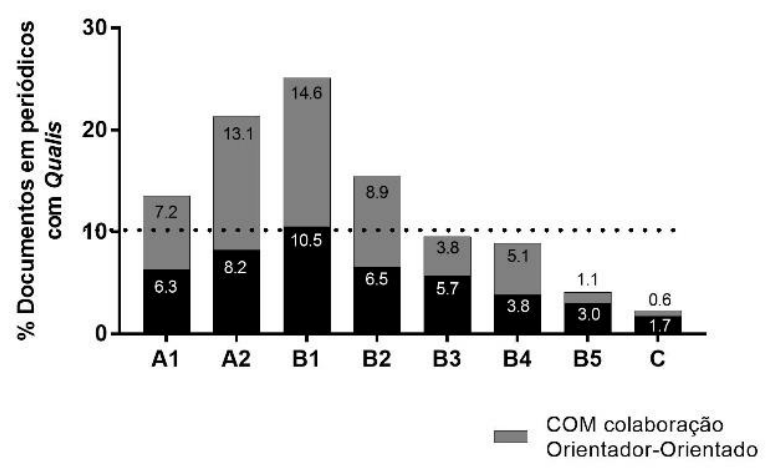

B

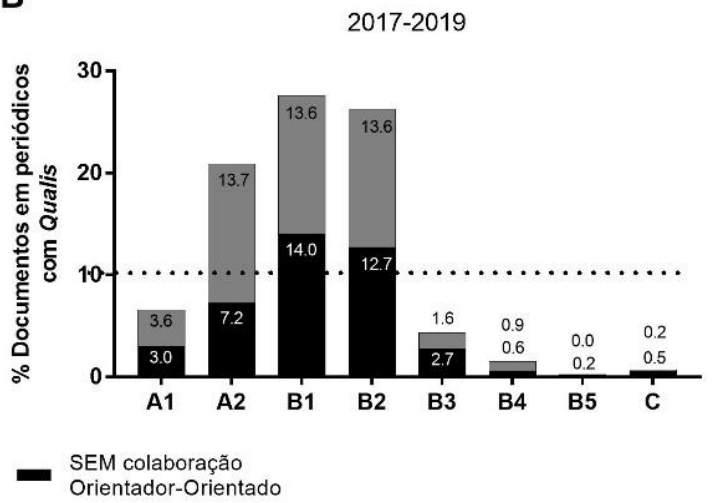

Figura 5. Percentuais de documentos em periódicos com Qualis pelo PPGQVS com e sem colaboração Docente-Orientado: (A) 2013-2016 e (B)* 2017-2019. Legenda: Figura 5B* Quadrienal Incompleta. No período de 2017-2019, identificaram-se $93(11,6 \%)$ documentos em periódicos sem Qualis e por isso não foram incluídos na figura 5. Segundo Barata (2016), os periódicos que ainda não possuem Qualis não foram utilizados pela comunidade científica da área no período avaliativo no

caso Quadrienal 2017. Fonte: Elaborado pelos autores, com base em dados da pesquisa.

Estes resultados conduzem à avaliação da distribuição de orientados (mestres e doutores titulados) entre os 112 docentes e a média de documentos (produção científica) por orientado. Tal abordagem se mostrou importante para responder o problema inicial desta pesquisa. Para isso, buscou-se estabelecer uma relação de genealogia acadêmica entre Docente-Orientado dos 1.275 documentos produzidos de 2013-219. Na Figura 5, além dos percentuais totais, visualiza-se a proporção de documentos com colaboração DocenteOrientado, que totalizou 665 documentos (52,1\%), sendo este o $n$ para as análises a seguir.

Na Tabela 1, dos 112 docentes, 102 titularam pelo menos um mestre e produziram 228 documentos com seus orientados, e 65 titularam pelo menos um doutor, produzindo 437 documentos. Evidenciou-se uma distribuição assimétrica no número de titulados (mestres e doutores) por docente e número de documentos. Contatou-se que 22 (21,6\%) docentes (com maior frequência de orientações concluídas de mestrado) foram responsáveis pela titulação de 187 (51,2\%) mestres e pela produção de 111 (48,7\%) documentos com Qualis. Para o nível de doutorado (Tabela 2), os percentuais são semelhantes: 15 (23,1\%) docentes (com maior frequência de orientações concluídas de doutorado) titularam 165 (54,6\%) doutores e produziram 247 (56,5\%) documentos. Portanto, há um grupo pequeno de docentes que concentra um pouco mais da metade de titulados e de produção científica. Interessante destacar que, ao analisar os docentes mais prolíficos, em termos de produção científica e de orientações concluídas de mestrado, sete deles também ocupam essa posição nas titulações de doutores. 
Tabela 1: Número de orientados (mestres titulados) por docente e número de documentos por orientado do PPGQVS (2013-2019)

\begin{tabular}{|c|c|c|c|c|c|c|c|c|c|}
\hline \multicolumn{10}{|c|}{ Mestres $(M)$ titulados } \\
\hline $\begin{array}{l}\text { ID } \\
\text { Grupo } \\
\text { (G) }\end{array}$ & $\begin{array}{c}N^{\circ} \text { de } \\
\text { Docentes }\end{array}$ & $\%$ & $\begin{array}{c}\mathrm{N}^{\circ} \text { de } \\
\text { Orientados } \\
\text { (M) por } \\
\text { Docente }\end{array}$ & $\begin{array}{l}\text { Total de } \\
\text { Mestres }\end{array}$ & $\%$ & $\begin{array}{c}\text { Total de } \\
\text { documentos }\end{array}$ & $\%$ & $\begin{array}{c}\text { Média de } \\
\text { documentos } \\
\text { por Orientado } \\
\text { (M) }\end{array}$ & $\begin{array}{c}\mathrm{N}^{\circ} \text { de } \\
\text { Docentes sem } \\
\text { documentos } \\
\text { publicados }\end{array}$ \\
\hline G 1 & 35 & 34,3 & 1 & 35 & 9,6 & 16 & 7,0 & 0,5 & 23 \\
\hline G 2 & 14 & 13,7 & 2 & 28 & 7,7 & 17 & 7,5 & 0,6 & 5 \\
\hline G 3 & 14 & 13,7 & 3 & 42 & 71,5 & 30 & 13,2 & 0,7 & 3 \\
\hline G 4 & 12 & 11,8 & 4 & 48 & 13,2 & 37 & 16,2 & 0,8 & 0 \\
\hline G 5 & 5 & 4,9 & 5 & 25 & 6,8 & 17 & 7,5 & 0,7 & 1 \\
\hline G 6 & 7 & 6,9 & 6 & 42 & 11,5 & 27 & 11,8 & 0,6 & 0 \\
\hline G 7 & 2 & 2,0 & 7 & 14 & 3,8 & 10 & 4,4 & 0,7 & 0 \\
\hline G 8 & 6 & 5,9 & 8 & 48 & 13,2 & 30 & 13,2 & 0,6 & 0 \\
\hline G 9 & 2 & 2,0 & 9 & 18 & 4,9 & 7 & 3,1 & 0,4 & 0 \\
\hline G 10 & 2 & 2,0 & 10 & 20 & 5,5 & 8 & 3,5 & 0,4 & 1 \\
\hline G 13 & 1 & 1,0 & 13 & 13 & 3,6 & 10 & 4,4 & 0,8 & 0 \\
\hline $\mathrm{G} 15$ & 1 & 1,0 & 15 & 15 & 4,7 & 4 & 7,8 & 0,3 & 0 \\
\hline \multirow[t]{2}{*}{ G 17} & 1 & 1,0 & 17 & 17 & 4,7 & 15 & 6,6 & 0,9 & 0 \\
\hline & 102 & 100,0 & 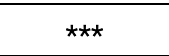 & 365 & 100,0 & 228 & 100,0 & 0,6 & 33 \\
\hline
\end{tabular}

Fonte: Elaborado pelos autores, com base nos dados da pesquisa.

Tabela 2: Número de orientados (doutores titulados) por docente e número de documentos por orientado do PPGQVS (2013-2019)

\begin{tabular}{|c|c|c|c|c|c|c|c|c|c|}
\hline & \multicolumn{9}{|c|}{ Doutores (D) titulados } \\
\hline $\begin{array}{l}\text { ID } \\
\text { Grupo } \\
\text { (G) }\end{array}$ & $\begin{array}{c}\mathrm{N}^{\circ} \text { de } \\
\text { Docentes }\end{array}$ & $\%$ & $\begin{array}{l}\mathrm{N}^{\circ} \text { de } \\
\text { Orientados } \\
\text { (D) por } \\
\text { Docente }\end{array}$ & $\begin{array}{l}\text { Total de } \\
\text { Doutores }\end{array}$ & $\%$ & $\begin{array}{c}\text { Total de } \\
\text { documentos }\end{array}$ & $\%$ & $\begin{array}{c}\text { Média de } \\
\text { documentos } \\
\text { por } \\
\text { Orientado (D) }\end{array}$ & $\begin{array}{c}\mathrm{N}^{\circ} \mathrm{de} \\
\text { Docentes sem } \\
\text { documentos } \\
\text { publicados }\end{array}$ \\
\hline G 1 & 16 & 24,6 & 1 & 16 & 5,3 & 19 & 4,3 & 1,2 & 6 \\
\hline G 2 & 13 & 20,0 & 2 & 26 & 8,6 & 22 & 5,0 & 0,8 & 4 \\
\hline G 3 & 3 & 4,6 & 3 & 9 & 3,0 & 23 & 5,3 & 2,6 & 0 \\
\hline G 4 & 9 & 13,8 & 4 & 36 & 11,9 & 64 & 74,6 & 7,8 & 0 \\
\hline G 5 & 4 & 6,2 & 5 & 20 & 6,6 & 20 & 4,6 & 7,0 & 0 \\
\hline G 6 & 5 & 7,7 & 6 & 30 & 9,9 & 42 & 9,6 & 7,4 & 0 \\
\hline G 7 & 5 & 7,7 & 7 & 35 & 11,6 & 51 & 11,7 & 7,5 & 0 \\
\hline G 8 & 3 & 4,6 & 8 & 24 & 7,9 & 42 & 9,6 & 7,8 & 0 \\
\hline G 10 & 1 & 1,5 & 10 & 10 & 3,3 & 13 & 3,0 & 7,3 & 0 \\
\hline G 11 & 3 & 4,6 & 11 & 33 & 10,9 & 41 & 9,4 & 1,2 & 0 \\
\hline G 12 & 1 & 1,5 & 12 & 12 & 4,0 & 17 & 3,9 & 7,4 & 0 \\
\hline G 14 & 1 & 1,5 & 14 & 14 & 4,6 & 11 & 2,5 & 0,8 & 0 \\
\hline \multirow[t]{2}{*}{ G 37} & 1 & 1,5 & 37 & 37 & 12,3 & 72 & 16,5 & 1,9 & 0 \\
\hline & 65 & 100,0 & 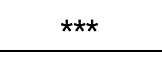 & 302 & 100,0 & 437 & 100,0 & 1,4 & 10 \\
\hline
\end{tabular}

Fonte: Elaborado pelos autores, com base nos dados da pesquisa.

Para o PPGQVS, esse desequilíbrio na distribuição de orientações concluídas e na distribuição de produção científica por docente é um agravante quando se analisa sob o 
viés do Sistema de Avaliação da CAPES, área de Ensino. Foi nestes dois quesitos que o PPGQVS obteve menores percentuais na avaliação Quadrienal 2017, conforme consta na sua Ficha de Avaliação (CAPES, 2017a). Além disso, é importante salientar que a ausência de publicações por parte de alguns docentes pode ter relação com as diferentes normativas (Regimento) de algumas sedes que não exigem publicação para a defesa, principalmente no mestrado (UFSM, 2014; FURG, 2017; UNIPAMPA, 2017).

A

\section{Mestres}

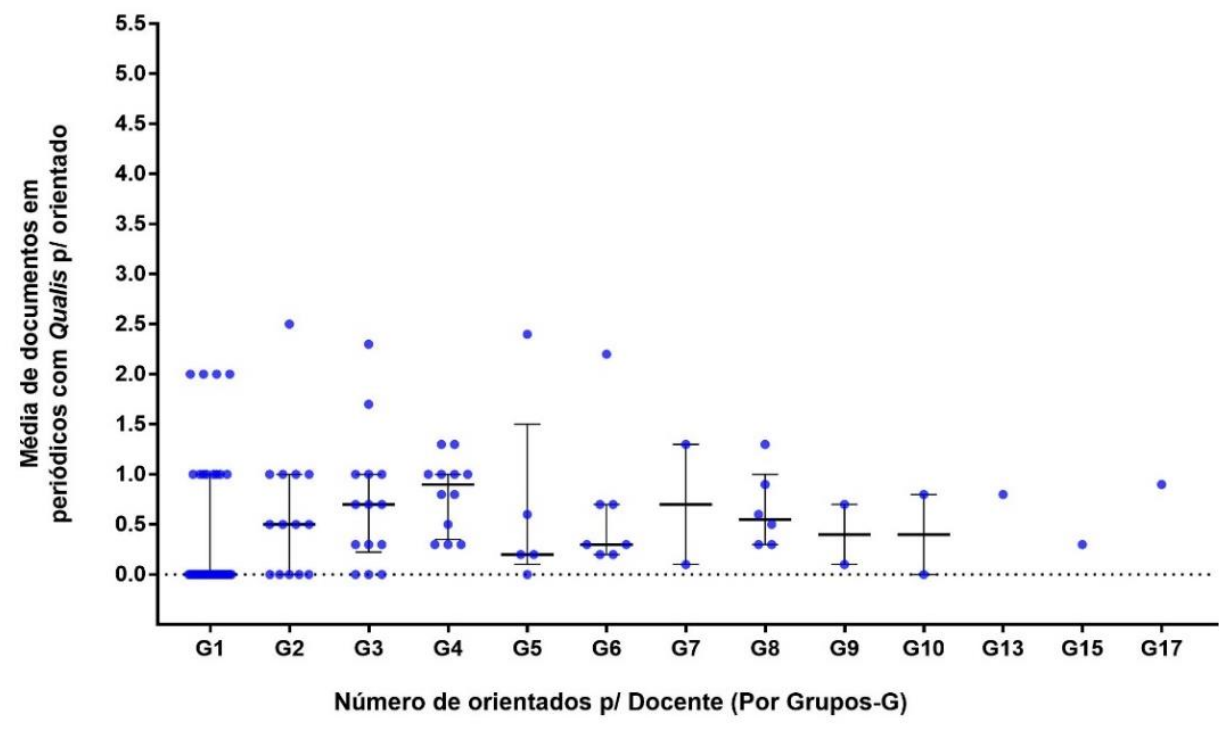

B

Doutores

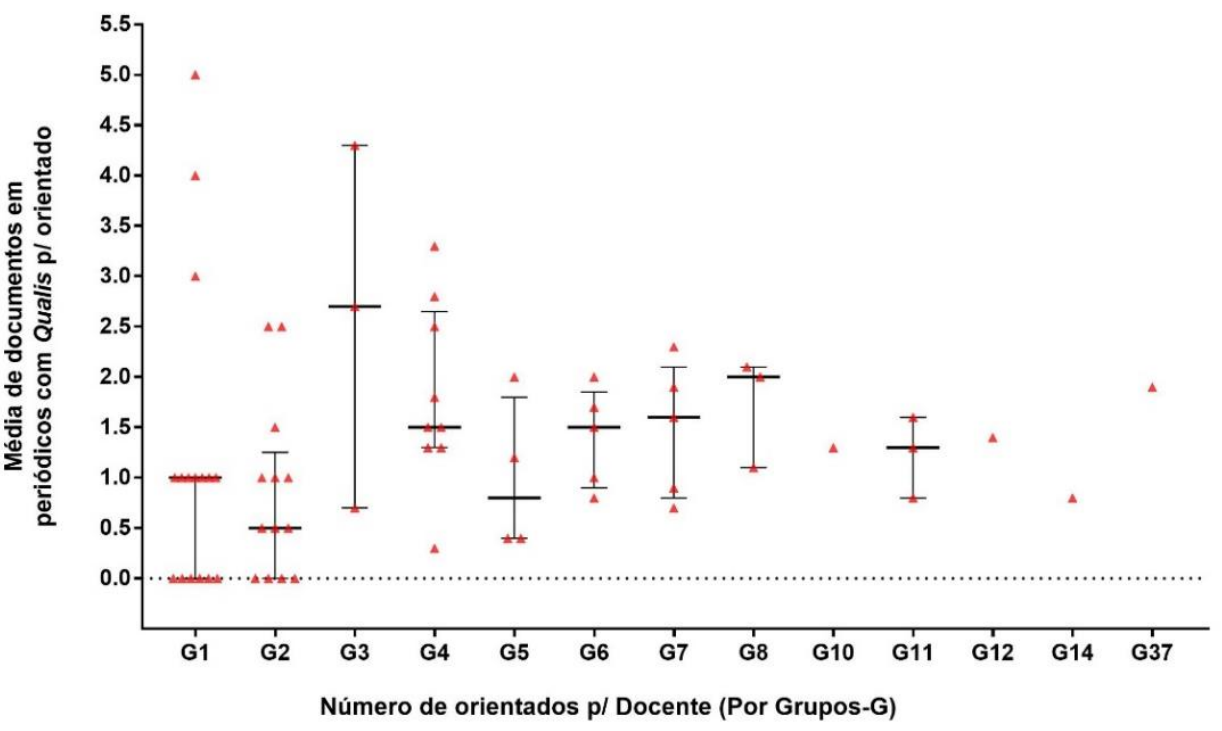

Figura 6. Orientados (A) mestres e (B) doutores titulados por docente e documentos por orientado do PPGQVS (2013-2019). Legenda: Teste ANOVA, com medianas. Fonte: Elaborado pelos autores, com base em dados da pesquisa.

Ao aplicar o teste estatístico ANOVA, para avaliar se o número de orientados (mestres e doutores titulados) por docente impacta na média de documentos por orientado, constatou-se que não há diferença significativa entre os grupos analisados: Mestres ( $P=$ 
0,9763) e Doutores $(P=0,6325)$. Portanto, o número de orientados por docente não impacta na média de documentos por orientado, Figura 6. Nesse contexto, a assimetria na distribuição da produção científica por docente pode estar associada ao número muito alto e/ou muito baixo de orientados por docente

No Quadro 1, são apresentados os resultados da análise dos temas priorizados nas pesquisas publicadas em periódicos com alta visibilidade (Qualis A1 e A2) pelos docentes com seus orientados. As 10 categorias criadas, resultantes da Análise de Conteúdo (BARDIN, 2009), possibilitaram dimensionar as contribuições PPGQVS para a construção de conhecimento científico para a área de Ensino e para a Educação em Ciências no país.

Os resultados apontam para uma prioridade em temas relacionados ao "Ensino de Ciências" (26,0\%), à "Formação de Professores" (24,3\%) e às "Políticas Educacionais" (15,7\%). Interessante observar que o número de documentos na categoria "Formação de Professores" aumentou expressivamente de um período para ao outro: 16 documentos (2013-2016) para 41 (2017-2019). Já em "Ensino de Ciências" e "Políticas Educacionais" o número de documentos se manteve estável: 34 para 27 e 16 para 21 documentos, respectivamente.

As categorias temáticas "Avaliação de Produtividade em Ciências" (5,5\%) e "Ensino de Matemática" (5,1\%), apesar de terem uma representação menor em comparação com as demais categorias, vem ganhando representatividade nas pesquisas no decorrer dos dois períodos analisados: de 3 para 10 documentos e de 1 para 11, respectivamente.

Os percentuais de documentos nas categorias "Avaliação de Políticas Públicas" (6,0\%), "Educação em Saúde" (5,1\%), "História e Filosofia da Ciência" (4,7\%), "Tecnologias de Informação e Comunicação" (4,3\%) e "Políticas de identidade e subjetividade na educação" $(3,4 \%)$ se mantiveram estáveis nos dois períodos.

Os estudos da categoria "Avaliação de Políticas Públicas" avaliaram, por exemplo, programas como o Ciências sem Fronteiras e o Programa de Pesquisa para o SUS. Estas pesquisas são decorrentes da parceria estabelecida pelo PPGQVS com instituições governamentais como a CAPES e o Conselho Nacional de Desenvolvimento Científico e Tecnológico (CNPq), que incentiva os servidores a realizarem mestrado e doutorado no PPG sem saírem de seus postos de trabalho (UFRGS, 2020). Por isso, muitas vezes, o objeto de estudo definido pelos servidores são os programas desenvolvidos pelas instituições onde atuam, o que sem dúvidas contribui para o aprimoramento das políticas públicas a partir dos resultados obtidos.

As categorias que apresentaram maior crescimento em número de documentos publicados foram: "Formação de Professores", "Avaliação de Produtividade em Ciências" e "Ensino de Matemática". Os documentos em periódicos com Qualis A1 e A2 produzidos pelo PPGQVS se constituem de temas de grande importância para a Educação em Ciência brasileira, discutindo assuntos que vão desde o currículo até análises das percepções dos estudantes e dos professores sobre ciência.

Em relação aos métodos utilizados nos documentos classificados na categoria "Ensino de Ciências", que foi a de maior frequência, constatou-se que na sua maioria são estudos empíricos (51 documentos). Nestes respectivos documentos, ficou evidente o interesse em adequar as aulas ao caráter prático, em que os estudantes participam na elaboração das práticas. Destacou-se também um expressivo número de documentos que utilizaram Análise Textual Discursiva (ATD), método aplicado pelos orientados (mestres e doutores) para analisar dados coletados via questionários e entrevistas feitas aos estudantes. Contudo, 
constatou-se que nesta categoria (Ensino de Ciências) há apenas 10 documentos de cunho teórico, o que demonstra poucos estudos de base teórica que traz discussão sobre pensadores e pedagogos.

Quadro 1: Temas priorizados nas pesquisas do PPGQVS (2013-2019) em periódicos com

Qualis A1 e A2

\begin{tabular}{|c|c|c|c|c|c|c|c|}
\hline \multirow{2}{*}{$\begin{array}{l}\text { Temas } \\
\text { Priorizados } \\
\text { Categorias }\end{array}$} & \multirow{2}{*}{ Tópicos Principais } & \multicolumn{6}{|c|}{$\begin{array}{c}\text { Frequência (235 documentos em Periódicos com } \\
\text { Qualis A1 e A2) }\end{array}$} \\
\hline & & $\begin{array}{l}2013- \\
2016\end{array}$ & $\%$ & $\begin{array}{l}2017- \\
2019 \\
\end{array}$ & $\%$ & Total & $\%$ \\
\hline $\begin{array}{l}01 \text { - Ensino de } \\
\text { Ciências }\end{array}$ & $\begin{array}{l}\text { Tópicos: Impacto do ensino interdisciplinar na percepção } \\
\text { dos estudantes; Concepções/percepções dos estudantes } \\
\text { sobre ciência; Modelos didáticos para ensino de ciências; } \\
\text { Ensino aprendizagem; Prevenção ambiental na escola; } \\
\text { Práticas pedagógicas para o ensino de ciências. Exemplo: } \\
\text { "Este trabalho apresenta os resultados referentes às } \\
\text { implicações pedagógicas no processo de ensino e } \\
\text { aprendizagem em Química e Biologia através da } \\
\text { utilização de temas geradores em uma escola pública } \\
\text { estadual [...]". }\end{array}$ & 34 & 35,4 & 27 & 19,4 & 61 & 26,0 \\
\hline $\begin{array}{l}02 \text { - Formação de } \\
\text { professores }\end{array}$ & $\begin{array}{l}\text { Tópicos: Linguagem, dinâmica discursiva e dinâmica de } \\
\text { interações sobre ciência; Complexidade; Pensamento } \\
\text { crítico; Pensamento reflexivo; Competência Profissional; } \\
\text { Formação interdisciplinar; Formação continuada; } \\
\text { Formação docente/profissional; Identidade Profissional; } \\
\text { Representações Sociais; Concepções sobre ciência; } \\
\text { Iniciação à docência. Exemplo: "O objetivo da pesquisa } \\
\text { [...] é discutir os saberes que caracterizam o educador, } \\
\text { bem como os atributos relacionados ao professor- } \\
\text { formador e sua pertinência para a constituição do } \\
\text { profissional crítico-reflexivo". }\end{array}$ & 16 & 16,7 & 41 & 29,5 & 57 & 24,3 \\
\hline $\begin{array}{l}03 \text { - Políticas } \\
\text { Educacionais }\end{array}$ & $\begin{array}{l}\text { Tópicos: Currículo; Programa Nacional do Livro Didático } \\
\text { (PNLD); Livro didático; Parâmetros Curriculares Nacionais } \\
\text { (PCNs); Projeto Político Pedagógico; Educação para } \\
\text { cidadania; Ferramentas didático-pedagógica; Pacto } \\
\text { Nacional pelo Fortalecimento do Ensino Médio } \\
\text { (Pnem)/Universidade Formadora; Avaliação do Enade e } \\
\text { o Enem; Rede Nacional de Educação e Ciência; } \\
\text { Inclusão/Acessibilidade na escola; Projetos de } \\
\text { fortalecimento à educação; Ambientes de } \\
\text { Aprendizagem. Exemplo: "Diferentes projetos para } \\
\text { promoção do acesso à ciência por meio da educação } \\
\text { têm sido desenvolvidos, como a Rede Nacional de } \\
\text { Educação e Ciência, que objetiva a melhoria do acesso à } \\
\text { ciência e do seu ensino por meio de cursos para } \\
\text { professores e alunos da rede pública de ensino. } \\
\text { Objetivamos estabelecer o discurso inicial de ciência } \\
\text { dessa Rede". }\end{array}$ & 16 & 16,7 & 21 & 15,1 & 37 & 15,7 \\
\hline $\begin{array}{l}04 \text { - Avaliação de } \\
\text { Políticas Públicas }\end{array}$ & $\begin{array}{l}\text { Tópicos: Avaliação de programas governamentais em } \\
\text { Educação e C\&T, tais como Ciências sem Fronteiras, } \\
\text { DINTER, Pesquisador Visitante Especial-PVE; Programa } \\
\text { de Pesquisa para o SUS, Programa Nacional de } \\
\text { Cooperação Acadêmica (Procad), Prêmio Capes de Tese. } \\
\text { Exemplos: "O estudo objetivou monitorar a execução e o } \\
\text { grau de implantação do Programa de Pesquisa para o } \\
\text { SUS: gestão compartilhada em saúde, no País". }\end{array}$ & 8 & 8,3 & 6 & 4,3 & 14 & 6,0 \\
\hline
\end{tabular}




\begin{tabular}{|c|c|c|c|c|c|c|c|}
\hline $\begin{array}{l}05 \text { - Avaliação de } \\
\text { Produtividade em } \\
\text { Ciências }\end{array}$ & $\begin{array}{l}\text { Tópicos: Uso de indicadores bibliométricos e } \\
\text { cientométricos para avaliar as características da } \\
\text { produção científica e a produtividade (autores, } \\
\text { instituições e países); Análise de Redes Sociais. Exemplo: } \\
\text { "O estudo teve como objetivos principais: mapear, } \\
\text { classificar e analisar descritivamente produções científicas } \\
\text { acerca do enfoque Ciência, Tecnologia e Sociedade, } \\
\text { publicadas entre } 2011 \text { e } 2015 \text { em revistas brasileiras". }\end{array}$ & 3 & 3,1 & 10 & 7,2 & 13 & 5,5 \\
\hline $\begin{array}{l}06 \text { - Educação } \\
\text { em Saúde }\end{array}$ & $\begin{array}{l}\text { Tópicos: Aspectos epistemológicos; Conteúdo de ensino } \\
\text { sobre Educação em Saúde; Estruturação curricular em } \\
\text { Educação em Saúde; Temáticas sobre drogas; } \\
\text { Percepções dos professores e dos estudantes quanto à } \\
\text { promoção da saúde; Promoção da saúde nos livros } \\
\text { didáticos. Exemplo: "A saúde dos adolescentes tem sido } \\
\text { pauta de discussões visto que esses sujeitos se } \\
\text { configuram como vulneráveis. Nesse trabalho tratamos } \\
\text { da temática do consumo de cigarros, álcool/drogas e } \\
\text { anabolizantes e procuramos analisar suas percepções } \\
\text { morais e éticas sobre a questão". }\end{array}$ & 7 & 7,3 & 5 & 3,6 & 12 & 5,1 \\
\hline $\begin{array}{l}07 \text { - Ensino de } \\
\text { Matemática }\end{array}$ & $\begin{array}{l}\text { Tópicos: Percepções, concepç̃̃es e saberes sobre } \\
\text { matemática; Práticas pedagógicas para o ensino de } \\
\text { matemática; Etnomatemática; Alfabetização Matemática; } \\
\text { Provinha Brasil de Matemática; Educação em } \\
\text { matemática; Olimpíadas de matemática; Ensino e } \\
\text { aprendizagem em matemática; Alfabetização; } \\
\text { Modelagem. Exemplo: "O presente artigo tem por } \\
\text { objetivo problematizar o discurso da Modelagem } \\
\text { Matemática na Educação Matemática, evidenciando uma } \\
\text { de suas descontinuidades históricas - do modelo à } \\
\text { modelagem". }\end{array}$ & 1 & 1,0 & 11 & 7,9 & 12 & 5,1 \\
\hline $\begin{array}{l}08 \text { - História e } \\
\text { Filosofia da } \\
\text { Ciência }\end{array}$ & $\begin{array}{l}\text { Tópicos: Epistemologia; Método científico; Aspectos } \\
\text { filosóficos e históricos; Campos conceituais; Didática das } \\
\text { ciências; Hermenêutica Filosófica à Educação Química; } \\
\text { Paradigmas da Educação em Ciências no Brasil. Exemplo: } \\
\text { "O presente trabalho traz algumas aproximações da } \\
\text { Hermenêutica Filosófica à Educação Química. Iniciamos } \\
\text { trazendo elementos que nos levaram a buscar aportes } \\
\text { da Hermenêutica Filosófica à Educação Química dentro } \\
\text { do grupo Comunidades Aprendentes em Educação } \\
\text { Ambiental Ciências e Matemática (CEAMECIM)". } \\
\end{array}$ & 5 & 5,2 & 6 & 4,3 & 11 & 4,7 \\
\hline $\begin{array}{l}09 \text { - Tecnologias } \\
\text { de Informação e } \\
\text { Comunicação } \\
\text { (TICs) }\end{array}$ & $\begin{array}{l}\text { Tópicos: Discursos coletivos sobre TICs; Uso das TICs no } \\
\text { ensino; Tecnologias digitais para o ensino de ciências e } \\
\text { matemática. Exemplo: "Neste artigo, são apresentados } \\
\text { os resultados da análise e reflexão sobre o uso de } \\
\text { tecnologias da informação e comunicação (TIC's) no } \\
\text { processo de ensino e aprendizagem da função } \\
\text { quadrática, no Ensino Médio, usando-se o software } \\
\text { gratuito Winplot". }\end{array}$ & 3 & 3,1 & 7 & 5,0 & 10 & 4,3 \\
\hline $\begin{array}{l}10 \text { - Políticas de } \\
\text { identidade e } \\
\text { subjetividade na } \\
\text { educação }\end{array}$ & $\begin{array}{l}\text { Tópicos: Nome civil; Nome social; Transgênero; } \\
\text { Educação em Gênero e Sexualidade; Gravidez na } \\
\text { adolescência. Exemplo: "Este trabalho tem por finalidade } \\
\text { analisar o impacto do direito ao uso do nome social por } \\
\text { transgêneros nos registros escolares". }\end{array}$ & 3 & 3,1 & 5 & 3,6 & 8 & 3,4 \\
\hline \multicolumn{2}{|r|}{ Total } & 96 & 100,0 & 139 & 100,0 & 235 & 100,0 \\
\hline
\end{tabular}

Legenda: Análise dos documentos com colaboração Docente-Orientado e em periódicos com Qualis A1 e A2, representando 35,3\% (235) do total de 665. Fonte: Elaborado pelos autores, com base nos dados da pesquisa.

Os resultados obtidos nesta pesquisa vão ao encontro das ideias apontadas por Cachapuz e colaboradores (2008), pois os enfoques de pesquisa da Educação em Ciências 
são de natureza interdisciplinar ao integrar temáticas de áreas como a Filosofia da Ciência, a História da Ciência, a Sociologia da Ciência e a Pedagogia Educacional.

\section{Considerações finais}

Os resultados desta pesquisa permitiram identificar algumas características do PPGQVS (Associação Ampla) no que diz respeito à formação de recursos humanos e à produção científica na área de Educação em Ciência.

O PPGQVS conta com um corpo docente multidisciplinar, indo ao encontro das diretrizes da área de Ensino (CAPES, 2019a). Um pouco mais da metade (52,1\%) da produção intelectual do programa apresentou uma relação de genealogia acadêmica entre Docente-Orientado (mestres e doutores titulados no período de 2013-2019). Pela dimensão do PPGQVS, este índice precisa ser melhor discutido em nível institucional com o intuito de se estabelecer estratégias de crescimento. Faz-se necessário analisar os demais documentos (49,9\%) que apresentaram ausência de genealogia acadêmica a fim de compreender as suas características, pois podem ser produções com orientados/egressos de outro período, produção com discentes ativos ou produções sem discente/egresso.

Em comparação com o período de 2013-2016, constatou-se um crescimento de 68,9\% de documentos em 2017-2019. No que diz respeito à quantidade versus visibilidade (Qualis) da produção científica do PPGQVS, há uma predominância de publicações em periódicos com Qualis B1.

A distribuição dos documentos publicados e as orientações concluídas por docente são assimétricas. Em relação à distribuição assimétrica da produção científica entre os docentes do PPGQVS (número de documentos), é possível associá-la à Lei de Elitismo de Price (PRICE, 1986), pois há um grupo pequeno de docentes que concentrou um pouco mais da metade da produção do PPQVS. Contudo, o número de orientados por docente não impacta na média de documentos por orientado, visto que não teve diferença significativa entre os grupos analisados. A média de documentos publicados pelos mestres titulados foi de 0,6 e dos doutores foi de 1,4 documentos. Nesse contexto, a assimetria na distribuição da produção científica por docente pode estar associada ao número muito alto e/ou muito baixo de orientados por docente, o que reforça a implementação de uma política interna que estipule um mínimo e/ou um máximo de orientações por docente a fim de atender as diretrizes da área de Ensino da CAPES.

A Análise de Conteúdo (BARDIN, 2009) aplicada neste contexto de exploração interpretativa de documentos da área de Educação em Ciências possibilitou evidenciar os temas priorizados nas pesquisas dos mestres e dos doutores titulados pelo PPGQVS num período de sete anos. A partir dos resultados obtidos, pode-se constatar que os temas pesquisados perpassam os saberes da área de Ensino e Educação em Ciências, bem como a sua equivalência com as linhas de pesquisa do PPGQVS. Dentre as categorias que tiveram maior frequência, destacaram-se "Ensino de Ciências" (26,0\%), "Formação de Professores" $(24,3 \%)$ e "Políticas Educacionais" (15,7\%). Essas categorias temáticas vão ao encontro das premissas da área de Ensino que espera que os egressos sejam agentes transformadores da sociedade e que possam contribuir na qualidade da educação no país. Na categoria "Ensino de Ciências", por exemplo, constatou-se que a maioria das pesquisas são de natureza prática, ou seja, pouco se investiu em pesquisas de cunho teórico. 
Outro resultado interessante em relação aos temas mais pesquisados foi a identificação de algumas categorias que apresentaram crescimento no número de documentos de um período para o outro, tais como: "Formação de Professores", "Avaliação de Produtividade em Ciências" e "Ensino de Matemática". Essa tendência de crescimento em pesquisas com essas temáticas demonstram o compromisso do PPGQVS em questões de suma importância para a educação como foram os enfoques dados às investigações sobre formação e competência profissional, linguagem e dinâmica discursiva dos docentes sobre ciências e seu fazer, bem como a análise de práticas pedagógicas para o Ensino de Matemática. Conforme Ferreira e Loguercio (2014, p. 46), a aplicação da Análise de Conteúdo é estratégica "[...] às pesquisas em ciências sociais e humanas, notadamente na área de Educação em Ciências, sobretudo por sua propriedade de desvelação de conteúdos [...]", que permitem traçar o perfil e tendências da área.

Estes resultados poderão servir de subsídio aos coordenadores do PPGQVS nas tomadas de decisões e no planejamento institucional, além de que o método aplicado poderá contribuir para uma Avaliação Institucional ou Autoavaliação dos PPGs da área de Ensino, conforme a CAPES vem estimulando em seus processos avaliativos (2019a).

Pretende-se analisar os temas priorizados nos demais documentos do PPGQVS com estratos do Qualis, bem como identificar os aspectos metodológicos em todas as categorias (abordagens, técnicas de coleta de dados e técnicas de análises). Almeja-se, também, investigar o perfil, o destino e a atuação profissional dos egressos do PPGQVS, constituindose em um amplo M\&A de desempenho institucional.

\section{Agradecimentos}

À CAPES e ao CNPq pelas bolsas concedidas.

\section{Referências}

BARATA, R. C. B. Dez coisas que você deveria saber sobre o Qualis. RBPG, v. 13, n. 30, p. 1340, jan./abr. 2016.

BARATA, R. C. B. Mudanças necessárias na avaliação da pós-graduação brasileira. Interface, v. 23, abr. 2019.

BARDIN, L. Análise de Conteúdo. Lisboa/Portugal: Edições 70, 2009.

BRASIL. Ministério da Educação. Parâmetros Curriculares Nacionais - Ciências Naturais. 1997. Disponível em: http://portal.mec.gov.br/seb/arquivos/pdf/livro04.pdf. Acesso em: 20 set. 2020.

CACHAPUZ, A.; PAIXÃO, F.; BERNARDINO LOPES, J.; GUERRA, C. Do Estado da Arte da Pesquisa em Educação em Ciências: Linhas de Pesquisa e o Caso "Ciência-TecnologiaSociedade". Alexandria Revista de Educação em Ciência e Tecnologia, v.1, n.1, p. 27-49, mar. 2008.

CAPES. Coordenação de Aperfeiçoamento de Pessoal de Nível Superior. Cursos recomendados e reconhecidos. Dados Básicos do Programa. Educação em Ciências Química da Vida e Saúde. 2020. Disponível em: 
https://sucupira.capes.gov.br/sucupira/public/consultas/coleta/programa/viewPrograma.jsf?p opup=true\&cd_programa=42001013098P9. Acesso em: 10 jun. 2020.

CAPES. Coordenação de Aperfeiçoamento de Pessoal de Nível Superior. Ficha de Avaliação. Brasília, 2019. Disponível em:

https://www.capes.gov.br/images/novo_portal/documentos/DAV/avaliacao/10062019_FichaAv alia\%C3\%A7\%C3\%A3o.pdf. Acesso em: 10 jun. 2020.

CAPES. Coordenação de Aperfeiçoamento de Pessoal de Nível Superior. Documento de Área: 46-Ensino. Brasília, 2019a. Disponível em:

http://capes.gov.br/images/Documento_de_\%C3\%A1rea_2019/ENSINO.pdf. Acesso em: 10 jun. 2020.

CAPES. Coordenação de Aperfeiçoamento de Pessoal de Nível Superior. Relatório de Avaliação 2013-2016: Área 46. Ensino. 2017. Disponível em:

http://capes.gov.br/images/stories/download/avaliacao/relatorios-finais-quadrienal2017/20122017-ENSINO-quadrienal.pdf. Acesso em: 10 jun. 2020.

CAPES. Coordenação de Aperfeiçoamento de Pessoal de Nível Superior. Ficha de Avaliação 2013-2016: PPGQVS. 2017a. Disponível em:

https://sucupira.capes.gov.br/sucupira/public/consultas/avaliacao/consultaFichaAvaliacao.jsf. Acesso em: 10 jun. 2020.

CAPES. Coordenação de Aperfeiçoamento de Pessoal de Nível Superior. Planilhas de Indicadores: Área 46. Ensino. 2017b. Disponível em:

http://avaliacaoquadrienal.capes.gov.br/home/planilhas-de-indicadores. Acesso em: 10 jun. 2020.

FERREIRA, M.; LOGUECIO, R. Q. A análise de Conteúdo como estratégia de pesquisa interpretativa em Educação em Ciências. REVELLI, v. 6, n. 2, p. 33-49, out. 2014.

FURG. Regimento do Programa de Pós-Graduação em Educação em Ciências: Química da Vida e Saúde - Sede FURG. 2017. Disponível em:

https://ppgec.furg.br/images/regimento_2017_a.pdf. Acesso em: 21 set. 2020.

GHENO, E. M. et al. Sistema de avaliação da CAPES: indicadores e procedimentos de monitoramento e avaliação de desempenho. Em Questão, v. 25, n. 3, p. 184-213, set./dez. 2019a.

GHENO, E. M. Indicadores e procedimentos de monitoramento e avaliação de desempenho complementares aos utilizados pelo sistema de avaliação da CAPES: Área Ciências Biológicas II. Tese. (Doutorado em Educação em Ciências) - Programa de Pós-Graduação em Educação em Ciências: Química da Vida e Saúde, Universidade Federal do Rio Grande do Sul, Porto Alegre, 2019.

GLÄNZEL, W. Bibliometrics as a research field: a courseon theory and application of bibliometric indicators. [Research Gate do autor]. 2003.

HILÁRIO, C.; GUTIERRES, R.; CABRINI, M. A influência da genealogia acadêmica na colaboração científica: um estudo no campo da Matemática no Brasil. Rev. Guillermo de Ockham, v. 15, n. 2. 2017.

KATZ, J. S.; MARTIN, B. R. What is research collaboration? Research Policy, v. 26, p. 1-18, 1997. 
MENA-CHALCO, J.; CESAR JUNIOR, R. M. ScriptLattes: an open-source knowledge extraction system from the Lattes platform. Journal of the Brazilian Computer Society, v.15, n. 4, p. 31-39, 2009.

MENEZES, L. C. Formar professores: tarefa da universidade. In: CATANI, B. et al. (Orgs.). Universidade, escola e formação de professores. São Paulo: Brasiliense, 1987.

NASCIMENTO, F.; FERNANDES, H. L.; MENDONÇA, V. M. O ensino de ciências no Brasil: história, formação de professores e desafios atuais. Revista HISTEDBR On-line, v. 10, n. 39, p. 225-249. 2010.

PAIM, A. Plataforma política do positivismo ilustrado. Brasília: Editora Universidade de Brasília, 1980.

PEREIRA, J. C.; CALABRÓ, L.; TEIXEIRA, M. R. F.; SOUZA, D. O. Redes de coautoria identificadas na produção científica em programa de pós-graduação da Universidade Federal do Rio Grande do Sul. RBPG, v. 11, n. 25, p. 731-753, set. 2014.

PRICE, D. J. S. Little science, big science... and beyond. New York: Columbia University Press, 1986.

SCHWARTZMAN, S. Changing roles of new knowledge: research institutions and societal transformations in Brazil. In: WAGNER, P.; WEISS, C. H.; WITTROCK, B.; WOLLMAN, H. Social sciences and modern states national experiences and theoretical crossroads. New York: Cambridge University Press, 1991.

SCHWARTZMAN, S.; CHRISTOPHE, M. A Educação em Ciências no Brasil. [S.I]: Instituto do Estudo do Trabalho e Sociedade; Academia Brasileira de Ciência, 2009.

UFRGS. Regimento do Programa de Pós-Graduação em Educação em Ciências: Química da Vida e Saúde - Sede UFRGS. 2017. Disponível em:

https://www.ufrgs.br/ppgeducacaociencias/ppgec/wp-content/uploads/2017/12/regimentoaprovado.pdf. Acesso em: 21 set. 2020.

UFRGS. Relatório do Sucupira para a avaliação de 2019 do PPGQVS. 2020. [Obtido via Secretaria do PPG].

UFSM. Regimento do Programa de Pós-Graduação em Educação em Ciências: Química da Vida e Saúde - Sede UFSM. 2014. Disponível em:

https://www.ufsm.br/app/uploads/sites/565/2019/04/regulamento-ppgec_3dez14.pdf. Acesso em: 21 set. 2020.

UNIPAMPA. Regimento do Programa de Pós-Graduação em Educação em Ciências: Química da Vida e Saúde - Sede UNIPAMPA. 2017. Disponível em:

http://cursos.unipampa.edu.br/cursos/ppgeducacaociencias/files/2017/11/regimento-internoppgecqvs-unipampa.pdf. Acesso em: 21 set. 2020.

VACCAREZZA, L. S. Ciencia, tecnología y sociedad: el estado de la cuestión en América Latina. Revista Iberoamericana de Educación, v. 18, p. 21-33. 1999.

VIGGIANI, E.; CALABRÓ, L.; SOUZA, D. O. Produção de orientadores de um programa de pós-graduação da Área de Ensino: análise da atuação simultânea em vários programas. Meta: Avaliação, v. 9, n. 27, p. 387-407, set./dez. 2017. 